Staff and student experiences of working together on pedagogic research projects:

Partnerships in practice

Rachel E. Maunder

The University of Northampton

Rachel.Maunder@,northampton.ac.uk

Tel: (44) 01604893727

ORCID: $\underline{0000-0001-6706-7515}$ 


\title{
Staff and student experiences of working together on pedagogic research projects:
}

\section{Partnerships in practice}

\begin{abstract}
The international interest in students as partners reflects the desire to involve students as active participants in higher education. Partnership working offers numerous beneficial outcomes but can be challenging to negotiate. Therefore, this study aimed to explore how student-staff partnerships in pedagogic research were interpreted and enacted. Twenty-one participants (12 staff, 9 students) who had been part of an institutional bursary scheme where students and staff work together in partnership on research projects related to learning and teaching participated in either a semi-structured interview or focus group. Data was analysed thematically. Conceptions of effective partnerships centred on notions of togetherness and mutuality. Considerations of hierarchy and the need for flexibility in working practices underpinned perspectives. The partnerships established between staff and students reflected three approaches, comparable to the established roles of research assistant, dissertation student and research team. Implications for practice and methodological considerations are discussed.
\end{abstract}

Keywords: students as partners; partnership; pedagogic research

\section{Introduction}


'Students as partners' $(\mathrm{SaP})$ is gaining credence in higher education, whereby students and staff work together on matters relating to teaching and learning (Mercer-Mapstone et al, 2017, p2). Such partnerships are "a collaborative, reciprocal process through which all participants have the opportunity to contribute equally, though not necessarily in the same ways" (Cook-Sather et al, 2014:6) - challenging traditional roles and requiring more democratic and reciprocal arrangements.

In this emerging and evolving field, there is a need to explore partnership praxis - as conceptualizations of partnerships intersect with experiences of partnership from the perspective of students and staff (Healey et al, 2014; Matthews et al, 2019). This paper therefore explores how staff and students working together on pedagogic research projects interpret the meaning of partnership, and how partnership working manifests in practice. The context for the study is an institutional bursary scheme called 'URB@N' (Undergraduate Research Bursaries at Northampton), where undergraduate students work in partnership with staff on learning and teaching research. The paper provides insight into partnerships in practice and encourages us to re-think existing student-staff relationships within the frame of partnership.

\section{Study context: the URB@N scheme}

The URB@N scheme (Undergraduate Research Bursaries at Northampton) provides funding for staff from faculties and professional services to appoint an undergraduate student researcher (sometimes two) to undertake pedagogic research in partnership with them. Projects are based on learning and teaching questions which staff are keen to investigate, with the potential to change practice and enhance the student experience. Previous topics include views on library induction, experiences of transition, perspectives on group work, engagement in online learning, and support for students with additional needs. Students 
receive a bursary, equating to approximately 50 hours work, and student-staff pairings present their findings and practical recommendations at the annual institutional learning and teaching conference. Since its inception in 2009 , the scheme has become an integral part of the university's learning and teaching activity. In this paper, accounts from staff and students who have participated in the scheme will be analysed to understand how partnerships are conceptualised, and how partnerships play out in the working relationships established.

\section{Features and challenges of partnership working}

Within the SaP movement, partnership is a mindset underpinned by values involving authenticity, inclusivity, reciprocity, empowerment, trust, challenge, community and shared responsibility (Healey et al, 2014, Healey \& Healey, 2018). Partnership means an active role for students, where they can participate in decision making and knowledge creation. The collaborative relationship between staff and students can take many forms, but the core aspect is the shifting staff and student roles and underpinning ethos (Bovill et al, 2016; Marquis et al, 2019; Matthews et al, 2019; Mercer-Mapstone et al, 2017).

Staff and students report various transformative outcomes from partnership working, including deeper engagement with and understanding of learning and teaching, improved confidence, shifting identities and educational enhancement (Cook-Sather et al, 2014; CookSather \& Luz, 2015). However, SaP redefines traditional staff-student relationships and can therefore be complex territory to navigate (Bovill et al, 2016; Marquis et al, 2016). There may be resistance, discomfort and uncertainty on both sides, with concerns about boundaries and capabilities (Bovill et al, 2016; Cook-Sather \& Luz, 2015). Some students have reported that despite valuing the partnerships and providing a unique perspective, they did not always feel like true partners with staff (Martens et al, 2018) - suggesting there can be a conceptual gap between the intentions of partnerships and how they are experienced. For example, 
power and equality are common terms in partnership literature but can be interpreted differently. The language and assumptions underlying partnerships and the process by which partnerships are enacted therefore need explicit attention (Healey et al, 2019; Matthews et al, 2019).

\section{Students as partners in pedagogic research}

$\mathrm{SaP}$ can operate in diverse ways, with varied interpretations and manifestations of partnerships (Healey \& Healey, 2018; Bovill, 2017; Little, 2011; Marquis et al, 2019). One approach is involving students in research activities with staff. For example, undergraduate research opportunity schemes give students a short term extra-curricular internship working with an academic researcher to undertake research (see John \& Creighton, 2011). These schemes are often based on disciplinary research and may not be framed as partnerships, but there are opportunities to adopt similar models for pedagogic purposes. Faculty spend much time on learning and teaching, and frequently grapple with pedagogic issues and questions, but it is less common for students to be genuine collaborators in this venture (Cook-Sather et al, 2014). Students are capable and keen to engage with pedagogic research as 'insiders' (Partridge \& Sandover, 2010) and working with staff on learning and teaching projects can stimulate their engagement and prompt reflection on their own learning and development (Bovill et al., 2011). Numerous benefits to students, staff and pedagogic practice are reported from such 'students as researcher' schemes (Sunley, 2015; Butcher \& Maunder, 2014). However, students and staff already frequently engage with each other for teaching, supervision and pastoral purposes. These established roles with differential status and hierarchy between staff and students may create barriers to partnership working for pedagogic purposes (Cook-Sather et al, 2014). Learning more about student-staff partnerships in this context, how they are built and their qualities and can therefore provide a useful framework to re-visit our understanding of existing faculty relationships. 
One study investigating students working with educational development teams on curriculum design or learning and teaching research (Marquis et al, 2016) found that the partnerships were reported to be transformative and troublesome - highlighting the benefits and challenges of enacting such relationships. Further research is needed in different contexts, especially as all staff in this study were educational developers, and all students were from the same course.

\section{Research aims}

The surge of interest in $\mathrm{SaP}$ and its status as an unfolding field is reflected in the diverse ways that partnerships are framed in the literature and the 'loose and evolving' theoretical foundations (Matthews et al, 2019, p.283). We need more empirical studies on partnership working, hence this study aims to explore how partnerships between staff and students are interpreted and enacted. The URB@N scheme at the University of Northampton, in which many staff and students across the university have participated, provides the opportunity to interrogate the intricacies of partnership relationships from the ground up. The study seeks to understand how staff and students working on pedagogic research projects interpret the meaning of working in partnership, and how partnership working between staff and students manifests in practice.

\section{Method}

\section{Research approach}

A qualitative approach utilising individual interviews and focus groups was conducted. Incorporating both methods facilitated methodological rigour - triangulating data generated from the one-to-one interviews. 


\section{Participants}

The target population for the study included all students and staff (called 'supervisors') who had been involved with the URB@N scheme, past or present. Everyone with available contact details was sent an e-mail explaining the project aims. Voluntary participation was highlighted, and individuals chose whether to respond via self-select sampling.

In total, 21 participants took part (12 students, and 9 staff members). They had not necessarily worked on the same projects. Staff represented a range of disciplines across academic faculties and professional services. Students were current and former undergraduate students with a broad disciplinary background. A focus group with 8 students took place, and all the remaining participants took part in an individual interview (4 student interviews, 9 staff interviews) either face to face or by telephone.

\section{Interview guide}

The focus group and interview guides were semi-structured. The URB@N project that staff and students participated in was a point of emphasis - enabling them to share what they had done and reflect on the process by which the work was achieved. The working relationship between staff and students was a key theme, exploring how communication was established, and how decisions were made. They were asked about their understanding of partnership, and the extent to which they felt their working relationship was a partnership.

\section{Data collection}

Staff and students expressing interest in participating were sent an information sheet, and a mutually convenient time for the interview or focus group was arranged. A research assistant independent to the URB@N scheme collected the data. 
The student focus group took place in a university teaching room. Ground rules and confidentiality between group members were discussed. The researcher facilitated the group using the interview guide and encouraged discussion between students about the topics raised.

The remaining data were collected via individual interviews. Interviews took place either in person in private venues on the university campus, or via telephone.

Participants were made aware of the risk of identification due to the target population of URB@N and scheme information being in the public domain. However, care was taken to remove identifiable information from transcripts and select quotes without any recognisable information. For this reason, specific details of the projects that participants worked on are not provided.

\section{Analytical steps}

Data was analysed thematically (Braun \& Clarke, 2006). The focus group and interviews were audio recorded and transcribed. Transcripts were read thoroughly several times, and coding notes made. Initial codes were combined across transcripts to enable examination of patterns. Multiple thematic maps were developed - capturing themes identified across the data set. Maps were consolidated and refined over time following ongoing reviews of the data and revisiting transcripts.

\section{Results}

Two main themes were identified: 1) Togetherness and mutuality represented the way participants interpreted the core features of partnership working, 2) Re-framing familiar roles 
represented how staff and students worked together on their projects. The working styles adopted reflected well-established practices akin to research assistant, research team, and dissertation student. Within each approach, the roles adopted by staff and students, and perceived ownership of the projects differed. Both themes were underpinned by the subtheme variety and flexibility - whereby participants recognised the different ways that partnerships could be enacted and the need to adapt working approaches to the circumstances. Additionally, the sub-theme hierarchy ran across both themes showing how participants reflected on power and status differentials between staff and students.

\section{Togetherness and mutuality}

When participants spoke about their interpretations of partnership, they consistently emphasised working together and mutual involvement. One staff member explained:

"the partnership is...coming together around the research project...sharing out responsibilities and just doing stuff together" (Supervisor, P10)

Another staff member described having common goals, and developing shared knowledge:

"we both were bringing something to the project relationship....The research area that we were looking at wasn't an area that I was particularly an expert in and we were actually developing our knowledge at the same time....and we had...very similar goals in terms of what we actually wanted out of it" (Supervisor, P4) 
Here the focus was on mutual learning, and both getting something from the experience. They were bringing different strengths and learning together. This view was mirrored by students:

$$
\begin{aligned}
& \text { "the word that comes to mind is collaboration. So it's the two of you } \\
& \text { pulling together your resources...to give a combined effort to reach a } \\
& \text { final goal and however you do that, whichever structure that partnership } \\
& \text { takes, that you have agreed, set deadlines and criteria that you'll be } \\
& \text { working together....it was two ways. It wasn't 'this is wrong', it's 'let's } \\
& \text { have a look at this'..." (Student, FG) }
\end{aligned}
$$

Partnership could take many forms, but the central qualities of partnership could feature in any of these. Both members of the partnership brought something valuable to the relationship, pooled resources and both contributed to the process. Rather than being judged ('this is wrong'), the student could question things and voice their opinions. Many participants spoke about the need for open debates, with both students and staff putting forward ideas to shape the course of the project.

$$
\begin{aligned}
& \text { "we talked through what we were going to do...we were a partnership } \\
& \text { sitting round the table thinking how we were gonna do it ...we're } \\
& \text { deciding together .....and we're divi-ing up the tasks and I'm not telling } \\
& \text { you what you should be doing...we're both learning a bit...he's not } \\
& \text { feeling like he's being told...what to do" (Supervisor, P1) }
\end{aligned}
$$

The analogy of 'sitting around the table' or 'sitting down together' was commonly used to describe what participants saw to be a democratic process of making decisions and reaching mutual agreements. Partnership was when both staff and students had a valuable point of view, and they listened to each other. The relationship was two-way, with joint responsibility, 
collective decision making, and shared allocation of tasks. Through describing these characteristics, many participants drew out factors that they believed partnership was not. In the above quote, 'being told what to do' was the antipathy of the partnership described. This view was corroborated by a student:

"You should not be ordering people... and they should not be ordering you, but you need to work out things... and be flexible about it...it's more having a choice...if you haven't got a choice then you being ordered to do things then that's not a partnership..." (Student, FG)

A partnership is seen to not involve dictating the direction of work. Instead, the student emphasises meaningful choice and involvement, where things are worked through collaboratively.

Interpretations of partnership did not necessarily require equal contribution or a 50:50 split of effort between staff and students. One student explicitly stated that partnership was not about the intricacies of how much each person does, more about how they worked together:

"to me partnership is working together and equal effort and it's not necessarily meaning ok I'll do one third and you two thirds and we'll half and half....it's just about respecting what other people say..." (Student, FG)

Although the student used the term 'equal effort', the subsequent part of the quote indicates that equal did not mean each person doing the same amount. Respect was emphasised, as well as both contributing. The way that effort was distributed between parties was important though, and where responsibility was unequal it impacted on perceptions of partnership. As one student explained: 
“...you're supposed to be helping them (supervisor) in a way and you're working towards the same goal, but I felt a little bit like it was my responsibility to do everything which isn't partnership" (Student, FG)

Here, partnership working was jeopardised by the student feeling a burden of responsibility, which was not appropriately shared with the supervisor. Things became too one sided and it compromised the partnership. There were gradients in the degree of joint working across the data. Some student-staff partnerships operated as a team where everything was shared equally, whereas others articulated arrangements where staff had differing levels of involvement. Importantly, partnerships were still seen to be possible in circumstances where students undertook more of the work, but the degree to which staff and students collaborated through this process were the key features. This was illustrated in one project where the staff member described a working model where the student worked independently:

"the student did the bulk, of the work....at each stage he came for feedback... but certainly the bulk of the work was done by him"

In a later part of the interview, the same staff member explained how the partnership worked between him and the student.

"I think we were partners...the fact that it was the student carrying out the research I think was excellent. He expressed his own position as a student but he was able to talk to other students at their level...and that resulted in very different outcomes than might have been achieved with a tutor standing in front of them...I think the fact that we bring different things to it...he brings the student 
perspective, student contacts and I can bring more of the academic overview and practical things...." (Supervisor, P3)

Inherent here was the idea that partnership means each person having different qualities and perspectives that can be brought together and used productively. Students' capabilities were recognised and utilised as well as those of staff. What were perceived to be the core features of partnership working could manifest in relationships with different working arrangements, and with workload distributed in different ways. The key was working together, valuing each other's perspectives and what each party brought to the relationship. As one student explained:

\footnotetext{
"we were equals we were working together to produce something...although he was my senior...it was our equal responsibility to produce a piece of work" (Student, P11)
}

Despite a perceived status differential between student and supervisor, partnership was established through joint working and shared responsibility to undertake the project.

\section{Re-framing familiar roles}

Student-staff pairings worked together in multiple ways. Mapping out the characteristics of these relationships and identifying similarities and differences enabled several 'working models' of partnership to be identified. Each model positioned the staff member and student differently, with shifting perceptions about who owned the project, and how roles were arranged. The models reflected re-enactments of existing working relationships within the sector. For example, one approach taken was like a research assistantship, whereby the student was the researcher - supporting the staff member to undertake designated tasks. The student was like an employee, with the staff member overseeing in their role as supervisor: 
"in a way the relationship became almost like they were staff who were line managed by me...it almost became like and they operate autonomously and independently so they do their thing, but it's steered very much by me" (Supervisor, P12)

In this model, staff members were in charge, with the student helping them. Supervisors owned the project, and had the final say about how things were done. However, the essence of partnership was still felt to be present, as reflected by one student's account:

"Obviously they (supervisors) were in charge of it and I was helping out but it felt more...on the same level...we were working together to achieve the same goal....If I had an opinion... it was easier to voice it and get involved in the debates and the discussions about what we're going to do and how we were going to do something.... and I felt that they really listened as well...I felt that I was involved every aspect..." (Student, P7)

This student felt part of the project and worked collaboratively with staff. Although she positioned them as 'owning' the research, she made a meaningful contribution to the research and was part of the decision making. This same student recognised the hierarchy in the relationship, but did not feel this compromised the partnership:

"they (the supervisors) were obviously in charge... you can't get away from that they were lecturers they knew what they were doing they'd done research before, they definitely knew more than I did (laughs).... there was communication and a partnership but, of course at the end of the day it's their work...." (Student, P7) 
There was a sense of inevitability about the fact that staff were in charge and ultimately responsible, but this team had struck a balance which enabled collaboration and mutual working between staff and students. This was not always the case however, and in one example a student described a relationship where she was primarily undertaking data collection but did not feel involved in the wider project.

"I don't really know what she's (supervisor) writing....she's got my data but what happens with it...don't have a clue" (Student, FG)

The lack of collaboration described by the student implied that this relationship was not operating as a partnership. The relative 'success' of this model was therefore reliant on the degree to which the students felt part of the decisions and actively involved in the process.

A second approach taken to the working relationship was analogous to a research team. Here, the supervisor and student assumed shared responsibility for the project and worked out each stage together. As one staff member explained:

"we'd sit down... establish whether there's any particular aspects that the student particularly liked to do or maybe not like to do...and then simply divide up the responsibilities...I always see it very much as a collaborative process...We'd generally do all parts of the process together..." (Supervisor, P10)

The staff member gave students choices and allocated tasks between the team - with all members (staff and students) participating in project activities. A similar working arrangement was articulated by a student:

"we set out...what we were going to do each week together...we would meet regularly... she gave us her telephone number.. our 
relationship was very on par...we were all given an even role"

(Student, FG)

The emphasis on 'we' in this quote implies a team effort, with everyone 'mucking in'. Communication was frequent and reciprocal between staff and student, and roles were shared. Reference to accessibility - both in terms of frequency of contact and being given the staff member's phone number, reflects a collegial relationship rather than traditional lecturerstudent where contact is typically more formally managed.

The third approach taken to partnership working was comparable to a dissertation student relationship, where the student works independently and the supervisor acts as a learning facilitator. As one student described:

\footnotetext{
"They (supervisors) gave us a lot of flexibility to construct the project in a way that we saw fit with their assistance...I was running it and they were helping to steer..." (Student, FG)
}

In this example the student owned the project and took the lead. The supervisor assumed a background role, providing advice and direction as needed. One member of staff said:

$$
\begin{aligned}
& \text { "I felt my role was not to tell them how to do something, not to tell } \\
& \text { them anything really, I felt that the project... should be a mostly } \\
& \text { student-led project... and be there to be guide, to look out for } \\
& \text { problems, to answer queries ...." (Supervisor, P6) }
\end{aligned}
$$

This staff member adopted a 'hands-off' approach - allowing the student to take ownership of the project. The onus was on the student to seek guidance, with the supervisor tailoring support and providing direction in response to student queries. The student had an important contribution to developing the direction of the project and making their own decisions, with the support of the staff member when they needed it. 
Partnerships were seen as possible across all working models providing the core features of partnership (namely, togetherness and mutuality as discussed in the previous theme) were present. For example, one student described a working relationship like the 'dissertation student' approach, but did not see this as a partnership:

“I thought that it was my project I take ownership...I didn't think it was in partnership I wasn't expecting her (supervisor) to do anything apart from be there when I asked a question...I got on with it on my own...I was the one in charge, she was the one supporting" (Student, FG)

The student's assessment about her own responsibility, and lack of expectation about regular supervisor input shaped their judgement about partnership. The staff member's contribution was minimal; hence it was not a partnership.

Perceptions of hierarchy also did not necessarily disrupt relationships. One student described how the seniority of the staff member did not detract from the partnership established between them:

\footnotetext{
"we'd sit down and talk about it decide where our strengths lay....and we'd agree the best way to split it between us...I certainly respected him as my senior but at the same time he appreciated my views and he never made me feel like he was in charge...I'd say we had an equal working relationship" (Student, P11)
}

The student felt able to express their opinions and the pair worked collaboratively. References to hierarchy were apparent across many of the transcripts, but both staff and students felt there was a way to establish a working relationship where both parties could 
collaborate, voice their opinions, and work together. However, there were apparent tensions and blurred boundaries on occasion. One staff member summed up their experience:

"That was quite a good experience for me...working with a student in a kind of a mentory kind of managery kind of way" (Supervisor, P1)

The 'mentory managery' term implied a struggle between leading and supporting the student. Although this is not positioned as a negative experience, it suggests that they were aware of their hybrid status in the relationship and tried to assume a blended role. Importantly, participants indicated that clarity in the working relationship, and having open discussions about this from the beginning was key in avoiding misunderstandings.

"There was definitely a hierarchy with me like I...collected all of the data, wrote the report...but that was...outlined in the initial meeting that I was the worker if you like and they were the steering wheel and they would just help me round...but I think because it was outlined and we set a roadmap right from the start and we set the deadlines you could then work around whose responsible for what... it's clear guidelines...it really helped to understand" (Student, FG)

Clarity in roles and responsibilities was established from the outset, so the student knew what was expected, which facilitated a smooth experience. In contrast, another student described the initial meeting with their supervisor which took a different direction:

“my supervisor gave me a title, wrote it down and I was like ok and I said "look are you going to set any timelines?" and she was like "no you're telling me just tell me what you're going to have done by when".... and I was like “oh” (laughs)" (Student, FG) 
There were differing expectations between student and supervisor, with the student being surprised by the independent framing of the work. This was not what the student anticipated, and the working relationship was not discussed, or any alternative options considered. As such, the 'togetherness and mutuality' features of partnership were absent.

Partnerships could operate in a variety of ways, and participants expressed the need for flexibility. There were differences between supervisors in the way they tended to work with students, there were differences within projects as relationships changed during the project, and there were also differences within supervisors depending on the student. One member of staff highlighted how student characteristics were a contributing factor to their working relationship:

\footnotetext{
"it was very much a negotiated role based on...her expertise or skills she'd developed in terms of research up until that point, and what she felt comfortable doing" (Supervisor, P13)
}

They evidently discussed how the relationship would work and a 'negotiated role' was constructed based on the needs and preferences of the student. Some staff members who had been involved in the scheme several times explained how they adopted different styles of working depending on the student. Similarly, the relational pattern sometimes adjusted over the course of a project as the research progressed. The need for flexibility, and openness to adapt to changing circumstances was eloquently highlighted by one staff member:

"I don't think there's one model relationship that, would work or perhaps we should even aspire to because it's going to be different....I think that partnership will perhaps vary... according to the characteristics of the individuals both the staff and the student, but also the expertise that that student has come in with" (Supervisor, P13) 
This suggests that individual characteristics of both staff and students will ultimately shape the nature of the relationship. Students too saw the need for flexibility in approach:

“...you can have the partnership how you like...different people work differently...the flexibility is a real key thing that made it work for me .." (Student, FG)

The key to effective partnerships was adjusting to context rather than adopting a rigid way of working. Continued discussion and two-way communication between staff and students, indicative of the 'togetherness' drawn out in the first theme, were vital ingredients in this ongoing negotiation.

\section{Discussion}

The findings show that staff and students viewed partnership as comprising core features of togetherness and mutuality. Effective partnerships were collaborative, with opportunity to discuss ideas, and with both parties working towards a shared goal. Equality between partners was about the collective distribution of effort and shared responsibility between parties, rather each undertaking the same amount of work. These conceptions resonate with existing literature on interpretations of partnership, with the need for meaningful student involvement at all stages, and commitment from all partners (Marquis et al, 2019; Martens et al, 2018; Healey et al, 2019). Participants did not misconceive equality as sameness (Healey et al, 2019) and instead reflected Cook-Sather et al's (2014: 6) partnership definition, where parties "contribute equally, though not necessarily in the same ways". 
Additionally, the findings showed how partnerships were enacted through different working patterns. The models of partnership described were comparable to existing roles of research assistant, dissertation student, and research team. Interpretations about ownership and responsibility varied depending on the model adopted, but staff and students saw that partnerships were possible within each of the models of practice providing the core features of mutuality and togetherness were present.

One might question the extent to which some of the relationships described were partnerships - and there is overlap with Martens et al's (2018) findings where some staff-student relationships did not operate in ways aligned to partnerships. For example, the research assistant model may not be a partnership because staff were managing the project, and the dissertation student model perhaps puts too much onus on the student. However, participants felt that partnership working was evident in these relationships providing the core aspects of open communication, discussion and shared decisions were present. There were also cases where staff and students gave clear indications of situations that were not partnerships, such as when either party did not feel able to contribute meaningfully to the direction of travel. Hence, what was and was not partnership were clearly distinguished in their accounts. Therefore, the findings illustrate the variety in types of relationships and models of working which participants captured in their interpretations of partnerships and provide tangible reference points to describe these approaches.

The findings also encourage reflection on traditional roles in higher education that are not necessarily called partnerships but could be reinterpreted as such. Partnership working differs from the existing relationships that faculty and students are used to occupying (Cook-Sather et al, 2014), and it is possible that the staff and students in this study built their partnerships by adapting working relationships they were used to. Common reference points (such as the dissertation student, research assistant, or research team models described here) are familiar 
and comfortable to staff and students, so may provide an interpretive framework to help SaP become more comprehensible (Matthews et al, 2019). The term 'partnership' can be problematic because it is laden with certain assumptions which also exert pressure to recreate textbook examples not reflective of the reality of these relationships (Healey et al, 2019). The models of practice described here could therefore provide a helpful prompt for staff and students embarking on partnerships to scaffold discussions about how they could work together, and explore the possible implications, in order to scaffold their entry into this new territory. In addition, they challenge us to consider how existing roles could be reframed or adapted within the umbrella of partnership, rather than partnerships being presented as entirely new or different.

Notions of power and hierarchy shaped participants' accounts in complex ways. There was recognition that hierarchy existed between staff and students, but many participants negotiated around this, enabling meaningful partnerships to operate. Healey et al's (2014) empowerment value suggests that power should be distributed 'appropriately' within a partnership, which is suggestive of its complexity. Partnership working involves challenging existing power dynamics and seeking new egalitarian ways of working (Little, 2011), yet partnerships are 'messy' and 'constrained by context' (Healey \& Healey, 2018, p6) so in seeking to understand partnerships in practice it is important to attend to contextual factors that may frame the relationship. There are elements of the URB@N scheme which may reproduce some of the power dynamics it is seeking to break down. For example, the research projects are initiated by staff, the students are selected by staff, and staff approve students' bursary payments. This creates a power differential, positioning staff as the gatekeeper. There are debates about students being paid for engagement in partnership initiatives (Healey et al, 2014), but a systematic literature review showed that student payments were common (Mercer-Mapstone et al, 2017), and there are ethical considerations about involving students 
without fair compensation. However, the current scheme characteristics may function to position staff as 'in charge'. This is difficult to overcome within institutional procedures, and the data shows that participants were seeking to find a collaborative working relationship and enact some of the core values of partnership within practical and institutional constraints. There is a need however to reflect on structural factors that may make partnership working more difficult.

There are also subtle ways in which power and hierarchy can frame partnership relationships. In the different partnership models described by participants, open dialogue and being able to contribute ideas was valued. However, when staff actively encourage articulation of ideas, their role as facilitators in this process could compromise equality between all parties (Curtis et al, 2012). It was evident that students tended to position staff as experts due to their greater research experience, implying that they assumed a novice identity (Curtis et al, 2012) and did not always recognise the expertise they brought as students (Healey et al, 2019). Given the entrenched cultural norms and roles in higher education, it can be difficult to overcome power dynamics completely, but the aim should be to seek to reduce them and establish more equal ground (Matthews et al, 2018). Hearing the accounts of participants as they grappled with these issues illustrates that working as partners is not straightforward, but that effective ways of working can be found. The findings should reassure others engaged in partnership working, and authenticate feelings of uncertainty, tension and discomfort likely to be felt (Cook-Sather et al, 2014).

The challenges presented by partnerships need to be tackled openly, with space created for staff and students to discuss these issues. Dialogue and negotiation are features of genuine partnership (Dwyer, 2018) and were regarded as important by the participants in this study. An implication arising from this research is the need for students and staff to discuss expectations and ways of working from outset. Issues arose when there was a mismatch 
between staff and student expectations and preferences, or where approaches were exercised without discussion or shared agreement. A further implication is the need to recognise the variety of approaches that can be taken to partnership working, and varying interpretations of what it means. Rather than a 'one size fits all' approach, SaPs represent a 'nexus' of relationships and roles (Dwyer, 2018, p1). Staff and students spoke about the importance of flexibility within a partnership, and between partnerships, accommodating different needs, preferences and circumstances. Who controls decision making and who has more voice will likely vary at different times, and depending on the context (Bovill, 2013), and "all parties need to be prepared to 'occupy' different spaces if it is to be successful” (p6) (Healey \& Healey, 2018).

A limitation of this study is that the interviews were based on staff and students recounting experiences. For some who had participated in the URB@N scheme previously, this involved recollections from some time ago. Memories may not be an accurate reflection of how the relationship worked at the time, and it would be worthwhile capturing experiences as they happen. Studying student-staff partnerships from their inception to developed stages would enable insight into the process of partnership working and how relationships shift over time in response to changing circumstances. Another methodological limitation is that students may have been reluctant to pass criticism on staff and feel pressure to report positive aspects (Mercer-Mapstone et al, 2017). Staff may also feel a similar pressure, especially as they had received institutional support through the URB@N scheme. It is possible that those staff and students who chose to participate in the study were those who had a positive experience to share, presenting a distorted picture. However, there were challenges highlighted which suggests that problems were not glossed over and participants felt able to express honest accounts. 


\section{Conclusion}

The study has shown that students and staff working together on pedagogic research projects interpret the meaning of partnership in various ways, but with a shared focus on togetherness and mutuality. Three models of partnership working were evident, which positioned ownership and responsibility for the project differently in each case. These models reflected established roles of research assistant, research team, and dissertation student, and therefore challenge us to re-understand these existing relationships within the frame of partnership. The importance of open communication about working relationships from the outset is needed, along with flexibility to context. Research utilising 'real time' methodologies to examine partnerships longitudinally are recommended, along with a consideration of institutional factors that may reproduce power dynamics between staff and students seeking to work in partnership.

\section{Acknowledgements}

Thanks to Jacqueline Stone and Chris Jackson for their research assistance.

\section{Declarations of interest}

There are no conflicts of interest to report.

\section{Funding}

This research was funded by The University of Northampton (Institute for Learning and Teaching) 


\section{References}

Bovill, C. (2013) Students and staff co-creating curricula: An example of good practice in higher education? In Dunne, E. and Owen, D. (Eds.) (2013a) The student engagement handbook: Practice in higher education (pp. 461-75). Bingley: Emerald.

Bovill, C. (2017). A framework to explore roles within student-staff partnerships in higher education: which students are partners, when and in what ways? International Journal for Students as Partners, 1(1).

Bovill, C., Cook-Sather, A., \& Felten, P. (2011). Students as co-creators of teaching approaches, course design and curricula: Implications for academic developers. International Journal for Academic Development, 16(2), 1-5.

Bovill, C., Cook-Sather, A., Felten, P., Millard, L., \& Moore-Cherry, N. (2016). Addressing potential challenges in co-creating learning and teaching: Overcoming resistance, navigating institutional norms and ensuring inclusivity in student-staff partnerships. Higher Education, 71, 195-208. doi:10.1007/s10734-015-9896-4

Braun, V. \& Clarke, V. (2006). Using thematic analysis in Psychology. Qualitative Research in Psychology, 3, 77-101.

Butcher, J. \& Maunder, R. (2014). Going URB@N: exploring the impact of undergraduate students as pedagogic researchers. Innovations in Education and Teaching International. $51(2), 142-152$.

Cook-Sather, A., Bovill, C., \& Felten, P. (2014). Engaging Students as Partners in Teaching and Learning: A Guide for Faculty. San Francisco: Jossey-Bass. 
Cook-Sather, A. \& Luz, A. (2015). Greater engagement in and responsibility for learning: what happens when students cross the threshold of student-faculty partnership. Higher Education Research \& Development, 34(6), 1097-1109.

Curtis, W., Goodson, A., McDonnell, J., Shields, S. \& Rob Wyness. (2012) Learning together and expanding horizons: reflections on a student-lecturer collaborative enquiry. Enhancing Learning in the Social Sciences, 4(3), 1-11, DOI: 10.11120/elss.2012.04030021

Dwyer, A. (2018). Toward the formation of genuine partnership spaces. International Journal for Students as Partners, 2(1),

Healey M., Flint, A., \& Harrington, K. (2014). Engagement through partnership: Students as partners in learning and teaching in higher education. York, England: The Higher Education Academy

Healey, M. \& Healey, R. L. (2018). "It depends": Exploring the context-dependent nature of 'Students as Partners' practices and policies. International Journal for Students as Partners, 2(1),

Healey, R., Lerczak, A., Welsh, K. \& France, D. (2019). By any other name? The impacts of differing assumptions, expectations, and misconceptions in bringing about resistance to student-staff partnership. International Journal for Students as Partners, 3(1).

John, J. \& Creighton, J. (2011). Researcher development: the impact of undergraduate research opportunity programmes on students in the UK. Studies in Higher Education, 36(7), 781-797.

Little, S. (2011) (Ed.). Staff-student partnerships in higher education. London: Continuum 
Marquis, E., Puri, V., Wan, S., Ahmad, A., Goff, L., Knorr, K., Vassileva, I. \& Woo, J. (2016). Navigating the threshold of student-staff partnerships: a case study from Ontario teaching and learning institute. International Journal for Academic Development, 21(1), 4-15.

Marquis, E., Jayaratnam, A., Lei, T. \& Mishra, A. (2019). Motivations, barriers, \& understandings: how students at four universities perceive student-faculty partnership programs. Higher Education Research \& Development, 38(6), 1240-1254.

Martens, S. E., Spruijt, A., Wolfhagen, I. H. A. P., Whittingham, J. R. D. \& Dolmans, D. H. J. M. (2018). A students' take on student-staff partnerships: experiences and preferences. Assessment \& Evaluation in Higher Education, online first. DOI:

$10.1080 / 02602938.2018 .1546374$

Matthews, K. E., Dwyer, A., Hine, L. \& Turner, J. (2018). Conceptions of students as partners. Higher Education, 76, 957-971.

Matthews, K. E., Cook-Sather, A., Acai, A., Dvorakova, S. L., Felten, P., Marquis, E. \& Mercer-Mapstone, L. (2019). Toward theories of partnership praxis: an analysis of interpretive framing in literature on students as partners in teaching and learning. Higher Education Research \& Development, 38(2), 280-293.

Mercer-Mapstone, L., Dvorakova, S. L., Matthews, K. E., Abbot, S., Cheng, B., Felten, P., Knorr, K., Marquis, E., Shammas, R. \& Swam, K. (2017). A systematic literature review of students as partners in Higher Education. International Journal for Students as Partners, 1(1).

Partridge, L \& Sandover, S. (2010). Beyond 'listening' to the student voice: The undergraduate researcher's contribution to the enhancement of teaching and learning. Journal of University Teaching \& Learning Practice, 7(2). 
Sunley, E. J. (2015). Bridging the gap: staff-student partnership through an undergraduate researcher scheme. Journal of Educational Innovation, Partnership and Change, 1(2), 